\title{
Moçambique: política e educação
}

Entrevistado: Antonio Domingos Braço

Entrevistadores: Jacqueline SIMÕES; Paulo GENOVESE; Vânia DARÉ e Viviane CASTRO

Entrevista realizada no dia 15 de maio de 2008

\section{GRUPO: Podemos começar com sua apresentação...}

Antônio Domingos Braço: Meu nome é Antônio Domingos Braço. Sou mais conhecido como Braço. Estou no Brasil faz um ano e meio, para um curso de mestrado na PUC São Paulo em educação e currículo. Sou moçambicano e tenho a formação de graduação em Pedagogia também aqui no Brasil. Atualmente, fazendo mestrado, estou vinculado à Universidade Pedagógica de Moçambique como docente nas cadeiras de Didática geral, Práticas pedagógicas e introdução à Pedagogia.

\section{G.: Pode falar um pouco sobre a história política e educacional de Moçambique?}

A. D. B.: É possível compreender Moçambique em partes históricas. Nós temos o período antes da colonização, mil quatrocentos e noventa e oito, antes da chegada dos portugueses. Não podemos falar nesse período de educação escolar, falamos de educação. No meu trabalho eu falo dos ritos de iniciação como educação. E depois nós temos o período da colonização que começa em mil quatrocentos e noventa e oito e vai até mil novecentos e setenta e quatro. Nesse período temos uma escolarização colonial que prima por toda a organização colonial e que vai querer fazer dos moçambicanos cidadãos portugueses. Os moçambicanos normalmente, nesse período, estudavam até a quarta classe que vocês chamam aqui de série e muitos não tinham condições de estudar. Mas em termos históricos existe um caminho: 
o Estado colonialista começa a se preocupar com escola no século XX, mil novecentos e quarenta. Começam a se preocupar, organiza-se a educação, torna-a obrigatória. Em 1975, nós temos a proclamação da República. Nesse período, Moçambique torna-se República Popular de Moçambique. O primeiro presidente vai ser Samora Michel. A partir daí, Moçambique assume constitucionalmente a ideologia marxista-leninista, o socialismo. Temos então outro período, da educação gratuita e obrigatória. Eu comecei a estudar em setenta e nove. Entrei na pré-escola, fui até a quarta. Estudavase numa escola até a quarta, chamado ensino primário. Quando se passava da quarta para a quinta, ia para outra escola chamada secundária: quinta e sexta. Nós chamamos hoje de antigo sistema. De sétima até a nona era o ensino secundário. E eu fiz da primeira até nona classe, toda no antigo sistema. Em mil novecentos e oitenta e dois cria-se um novo sistema, totalmente enraizado na perspectiva do socialismo, cria-se uma lei que regula o sistema nacional de educação. Aí esse sistema vai criar algumas diferenciações. Uma das diferenças é que a pré-escola se desvincula da escola. Então as crianças entram diretamente na escola, no primeiro ano, e a escolaridade passa de onze anos para doze anos, até o ensino médio. Se antes você tinha a escola obrigatória, era da pré-escola até a nona classe. Já o ensino médio não era obrigatório apesar de ser gratuito. Em mil novecentos e oitenta e dois o ensino vai se dividir em ensino primário, de primeira a quinta; em ensino primário de segundo grau, de sexta a sétima; o ensino secundário do primeiro grau, da oitava até a décima. E depois em ensino médio, décima primeira e décima segunda, e a pessoa ia para a universidade. Cabe ressaltar que quando se termina o ensino primário, você tem opções, ou o ensino geral ou o ensino técnico.

\section{G.: Tendo em vista todas essas reformas educacionais que você acaba de relatar, o que, em sua opinião, explica índices ainda tão altos de analfabetismo em Moçambique?}


A. D. B.: Já da colonização nós herdamos uma taxa de analfabetos de 96 por cento. Isso em mil novecentos e setenta e cinco. Nos anos seguintes a taxa foi diminuindo, parece que estava entre sessenta, setenta, porém alta ainda. O que acontece? A progressão da escola no campo foi muito lenta. Moçambique ficou independente em setenta e cinco, mas em setenta e oito começou uma nova guerra civil. Então a guerra destruiu, não cabe aqui detalhar o quanto destruiu do tecido social, da própria infra-estrutura, da mobilidade das pessoas, a questão dos refugiados, o deslocamento das pessoas para lugares considerados mais seguros, outras províncias, outros países... Mas destruição foi muito grande.

\section{G.: Qual a razão dessa guerra civil, se o país já estava independente?}

A. D. B.: É uma questão ideológica. Eu penso que para compreender as guerras todas é preciso compreender a questão da Guerra Fria, dos Estados Unidos. Moçambique ficou independente em setenta e cinco, assumiu a teoria marxista-leninista como a orientadora. Mas Moçambique era vizinho da África do Sul que tinha outro regime. E os Estados Unidos estavam vivendo confrontos ideológicos e político com as ex União Soviética. Então todo este cenário fez com que eclodisse dentro de Moçambique confrontos ideológicos que antes mesmo da independência já existiam. Porque o fato de se assumir o marxismo não foi pacífico. Não é em todos os lugares pacífico se assumir uma certa ideologia. A história do Brasil também mostra isso... Senão não existiriam tantos partidos políticos. Mas o marxismo fechou a possibilidade do diálogo com as correntes adversárias. Então este fechamento foi um dos motivos além dos motivos étnicos. Mas o fechamento foi o que historicamente mais pesou. Você vai ter de um lado, uma parte sendo financiada pela União Soviética, de tal forma que a maior dívida de Moçambique é com a União Soviética em armamentos. E vais ter outro grupo financiado pelo ex-regime da Rodésia, totalmente liberal, do 
outro lado. Este é um dos motivos. Mas os motivos mesmo da guerra vão ser conhecidos mais a frente. Aquele é o que é proclamado oficialmente, mas eu penso que existem motivos pessoais, ambições das pessoas que lutaram, havia promessas, a questão do divisionismo: este é de cá, este é de lá... Parece ter influenciado também. Só que isso, historicamente, não aparece. Porque a FRELIMO que lutava pela independência já nasce duma fusão de movimentos diferentes, que tinham propostas diferentes. Mas como o inimigo era comum, nossas diferenças acabam. No momento em que já não temos o inimigo comum, nossas diferenças surgem à tona.

\section{G.: Trabalhando com Educação e Currículo, sendo africano e conhecendo a realidade cultural do Brasil após tantos anos de estudo nesse país, quais contribuições seriam relevantes para a prática em sala de aula depois da lei 10639/2003 que trata da inclusão de assuntos pertinentes à história de África?}

O brasileiro, por exemplo, desconhece muito sobre África. Mas parece que o vosso currículo é muito fechado, só fala da Europa e dos Estados Unidos, esquece das outras coisas. É preciso saber, por exemplo, que a língua oficial em Moçambique é o português, o resto é dialeto, é marginalizado. Mas foram cadastradas vinte e sete línguas oficiais, não são dialetos, esses são mais de cem! Além disso, é também preciso destacar a questão das independências de África, a própria questão da escravatura... Porque às vezes as pessoas perguntam: "Como é que vocês se relacionam com a questão da escravatura?” A escravatura é uma questão que está sempre aqui no Brasil. Nós não temos lastro porque não se teve escravos em África, pelo menos não da mesma natureza que aqui no Brasil. Portanto, a natureza da escravidão praticada no Brasil é de quando se tira uma pessoa de África, por exemplo, e se leva para uma terra alheia. É uma questão que as crianças e os mesmo os adultos, precisam compreender. Os portugueses não levaram para 
o Brasil ou para outro país qualquer africano. Os portugueses quando chegaram ao Brasil tinham dificuldade de explorar as minas de Minas Gerais. África já tinha um conhecimento do minério de longa data. Os portugueses pegaram os africanos que sabiam a técnica do minério e levaram para Minas Gerais. Mas isso a história não diz. Os portugueses não tinham técnica de plantação de arroz. A África é que começou com o tipo de pastoreio de animal solto. Os portugueses não tinham isso. Em Portugal o cuidado dos animais era cercado. Vieram os africanos que dominavam as técnicas de plantio e de pastoreio. Então quando se diz que os africanos que foram levados da África eram apanhados a solta, isso não corresponde à verdade. Porque as pessoas que vieram para cá escravizadas dominavam as técnicas.

\section{Curriculum do entrevistado:}

\begin{tabular}{l|l|} 
Antonio Domingos Braço é professor da \\
Universidade Pedagógica de Moçambique e \\
mestrando na área de Educação e Currículo na \\
Pontifícia Universidade Católica de São Paulo. \\
Nasceu em Moçambique.
\end{tabular}

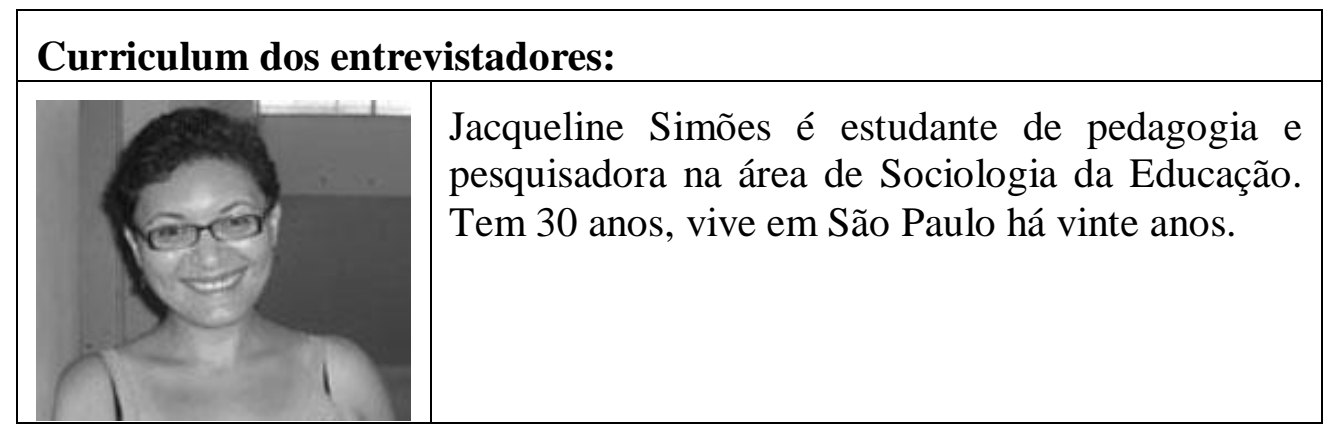




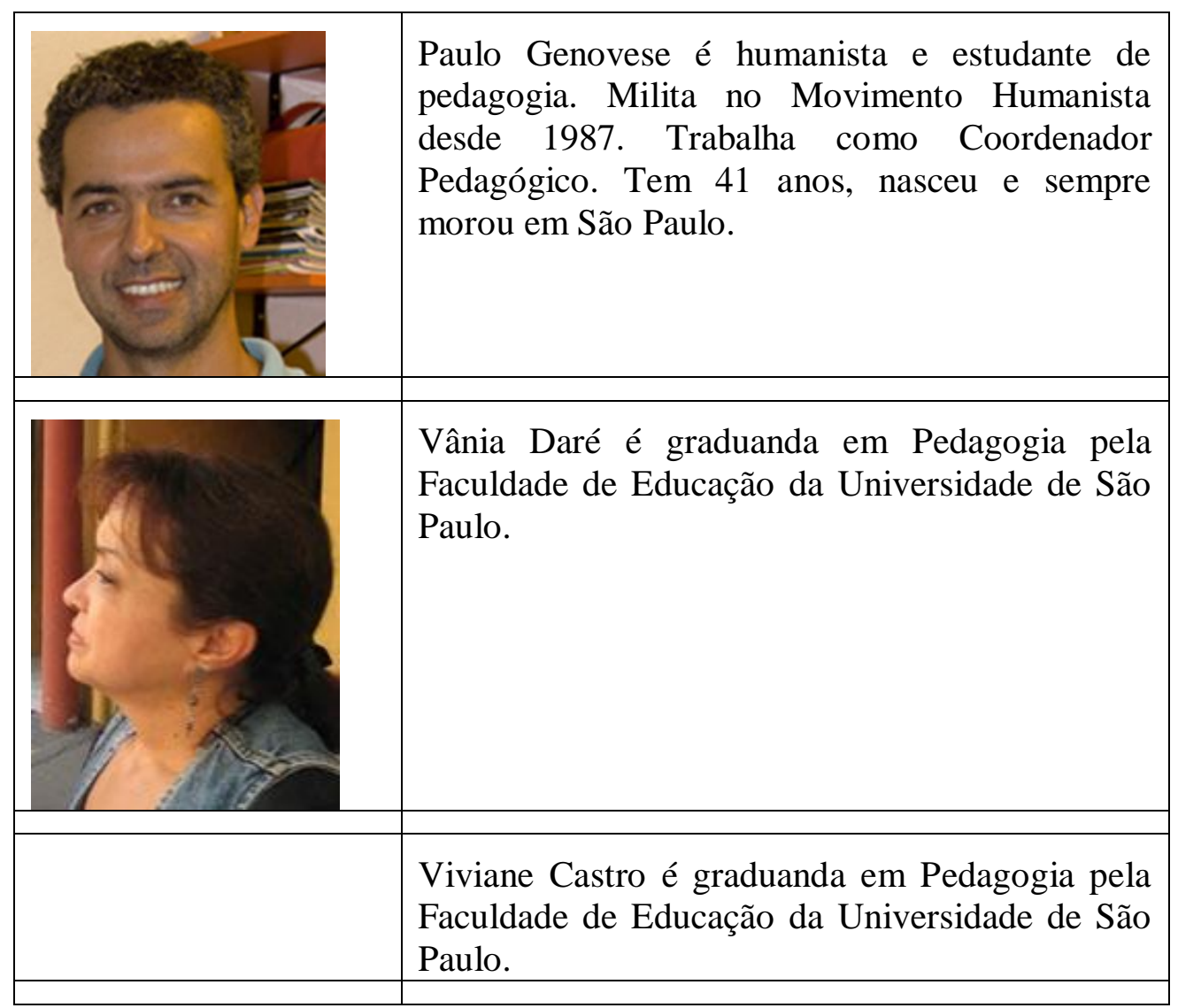

Entrevista realizada no dia 15 de maio de 2008 pelo grupo de estudantes da Faculdade de Educação da USP (Jacqueline SIMÕES, Paulo GENOVEZE, Vânia DARÉ e Viviane CASTRO) com o pedagogo moçambicano Antônio Domingos Braço. $O$ trabalho foi realizado nas dependências da Universidade da Cidadania Zumbi dos Palmares (UNIPALMARES) localizada na Rua Padre Luís Alves de Siqueira, nº 640, na Barra Funda em São Paulo.

\section{Como citar esta entrevista:}

SIMÕES, Jacqueline; et all. Moçambique: política e educação. Entrevistado: Antonio Domingos Braço. Revista ACOALFAplp: Acolhendo a Alfabetização nos Países de Língua portuguesa, São Paulo, ano 4, n. 7, 2009. Disponível em: <http://www.acoalfaplp.net>. Publicado em: setembro 2009. 